\title{
The hypertension caused by stenosis of renal arterie
}

\author{
Hidajeta Begić ${ }^{1}$, Husref Tahirovićn ${ }^{2}$ Snježna Zulić ${ }^{1}$
}

${ }^{1}$ Department of Paediatrics, Tuzla

${ }^{2}$ Department for Research and Education

University Clinical Centre Tuzla

Tuzla, Bosnia and Herzegovina

bbs.enes@bih.net.ba

Tel.: + 38735303 740; Fax: + 38735303740

Received: 27 August 2010; Accepted: 25 October 2010

Copyright $\odot 2011$ by Academy of Sciences and

Arts of Bosnia and Herzegovina. E-mail for

permission to publish:amabih@anubih.ba
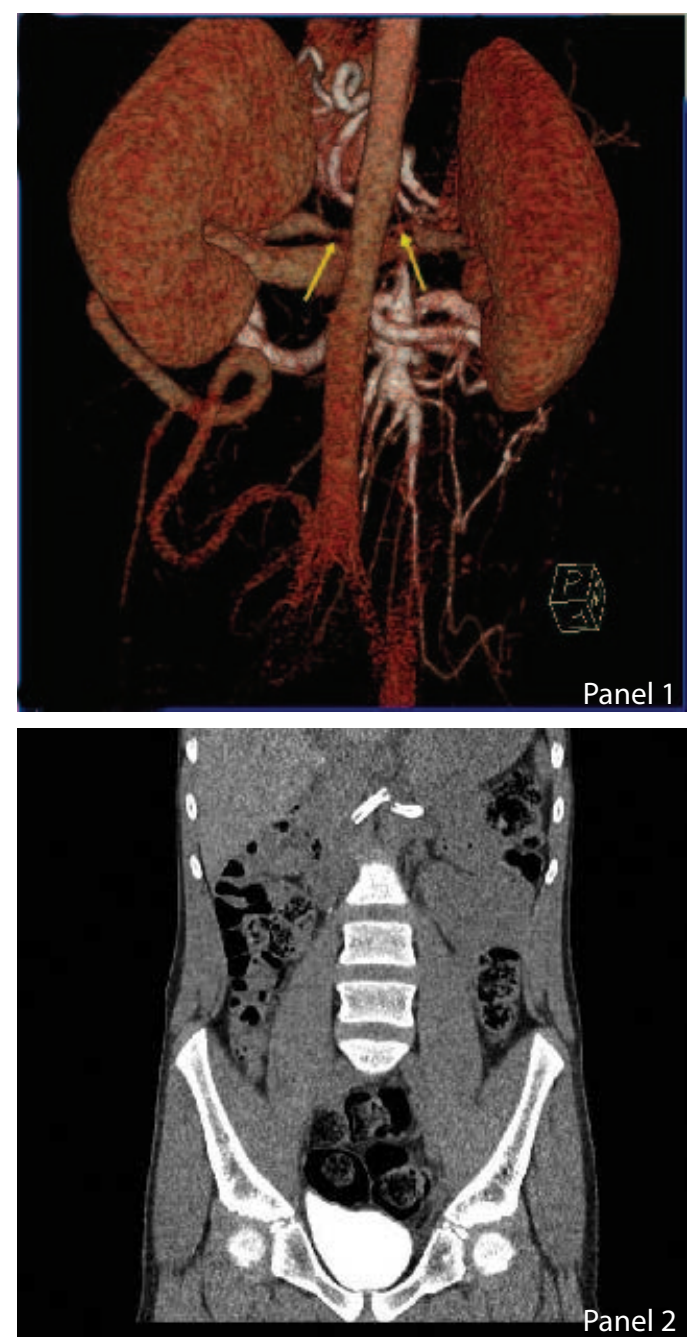

An otherwise healthy, 12.5-year-old male presented with sudden onset chest pain, was admitted to hospital for elevated blood pres- sure. Physical examination showed systolic heart murmur grade $2 / 6$ in the aortic area with abdominal vascular murmur and normal peripheral pulses. Blood pressure was elevated: (left arm) 170/110 mmHg, (left leg) 185/115 mmHg. The plasma renin activity $(6.5 \mathrm{nmol} / \mathrm{l} / \mathrm{h})$ was elevated. Renal function was normal. Doppler blood flow from both renal arteries showed a suspected mild obstruction. Magnetic resonance imaging of the kidneys and suprarenal glands were normal. Computerised tomography angiography demonstrated the normal dimension of the abdominal aorta with narrowed origins and proximal segment of both renal arteries with "string-of-beads" appearance (range occlusion of right renal artery was $90 \%$ and of the left renal artery $95 \%$, with poststenotic dilatation) (Panel 1). Several occlusions of the origin of the celiac trunk and the origin of the superior mesenteric artery were identified. Extensive collateralization from the inferior mesenteric artery and Riolan arcus existed. The diagnosis was renovascular hypertension caused by several stenosis of both renal arteries. Medical treatment of arterial hypertension was started, and the patient underwent interventional revascularisation. Bilateral percutaneous transluminal angioplasty of the renal arteries was performed. Follow-up computerised tomography showed a good stent position (Panel 2). At two months follow-up, Doppler ultrasound examination showed a great improvement in the blood flow in both renal arteries. Medical antihypertensive therapy was gradually reduced, after three months he had an uneventful recovery, his blood pressure remained normal with no drug treatment.

Conflict of interest: The authors declare that they have no conflict of interest. This study was not sponsored by any external organisation. 